\title{
Estimation of the population attributable fraction of road- related injuries due to speeding and passing in Iran
}

\author{
Fatemeh Khosravi Shadmani ${ }^{1}$, Hamid Soori ${ }^{2}$, Kamyar Mansori ${ }^{3,4}$, Manoochehr Karami ${ }^{5}$, \\ Erfan Ayubi ${ }^{6,7}$, Salman Khazaei ${ }^{5}$ \\ ${ }^{1}$ Modeling in Health Research Center, Institute for Futures Studies in Health, Kerman University of Medical Sciences, Kerman; ${ }^{2}$ Department of \\ Epidemiology, School of Public Health, Safety Promotion and Injury Prevention Research Center, Shahid Beheshti University of Medical \\ Sciences, Tehran; ${ }^{3}$ Social Determinants of Health Research Center, Kurdistan University of Medical Sciences, Sanandaj; ${ }^{4}$ Department of \\ Epidemiology, School of Public Health, Iran University of Medical Science, Tehran; 'Department of Epidemiology, School of Public Health, \\ Hamadan University of Medical Sciences, Hamadan; ${ }^{6}$ Department of Public Health, School of Public Health, Zabol University of Medical \\ Sciences, Zabol; ' 7 Department of Epidemiology and Biostatistics, School of Public Health, Tehran University of Medical Sciences, Tehran, Iran
}

OBJECTIVES: Speeding and passing are considered to be the main human factors resulting in road traffic injuries (RTIs). This study aimed to estimate the population attributeable fraction (PAF) of speeding and passing in RTIs in rural Iran during 2012.

METHODS: The contribution of speeding and passing to RTI-related morbidity and mortality was estimated using the PAF method. The prevalence of speeding and passing was obtained from the national traffic police data registry. A logistic regression model was used to measure the association between the above risk factors and RTIs.

RESULTS: Speeding accounted for $20.96 \%$ and $16.61 \%$ of rural road-related deaths and injuries, respectively. The corresponding values for passing were $13.50 \%$ and $13.44 \%$, respectively. Jointly, the PAF of these factors was $31.63 \%$ for road-related deaths and $27.81 \%$ for injuries.

CONCLUSIONS: This study illustrates the importance of controlling speeding and passing as a high-priority aspect of public-health approaches to RTIs in Iran. It is recommended that laws restricting speeding and passing be enforced more strictly.

KEY WORDS: Accidents, Traffic, Risk factors, Prevalence, Population attributable fraction, Iran

\section{INTRODUCTION}

Road traffic injuries (RTIs) are an important public health problem worldwide [1]. In low and middle-income countries, this factor accounts for approximately $85 \%$ of deaths and $90 \%$

\section{Correspondence: Hamid Soori}

Department of Epidemiology, School of Public Health, Safety Promotion and Injury Prevention Research Center, Shahid Beheshti University of Medical Sciences, Tabnak Avenue, Evin, Tehran 19836, Iran

Tel: +98-2122431993, Fax: +98-2122439980, E-mail: hsoori@yahoo.com

Received: May 13, 2016, Accepted: Aug 29, 2016, Published: Aug 29, 2016

This article is available from: http://e-epih.org/

(C) 2016, Korean Society of Epidemiology

(C) This is an open-access article distributed under the terms of the Creative Commons Attribution License (http://creativecommons.org/licenses/by/4.0/), which permits unrestricted use, distribution, and reproduction in any medium, provided the original work is properly cited. of the annual disability-adjusted life years lost due to accidents are associated with RTIs [2]. In Iran, RTIs have an annual incidence of 32 per 100,000, and are the second-largest cause of mortality, the largest cause of years of life lost due to premature death, and the most common cause of injuries [3]. RTIs account for $29 \%$ of total mortality in Iran [4], and have caused the loss of 1.3 million life-years in Iran [5]. Therefore, the prevention of this type of injury should be a serious consideration, and recognizing the dangers associated with this risk factor is a prerequisite for its prevention.

Human-associated risk factors make the greatest contribution to the incidence of RTIs. Of the causes of RTIs, human elements are more complex than environmental elements [6]. Among the risk factors associated with RTIs, speeding is one of the most prevalent factors, and affects both the severity of injuries and the risk of a crash [7]. High speed shortens drivers' reaction time 
and leads to increased errors in driving [8]. Mao et al. [9] demonstrated that exceeding the speed limit was a factor associated with the occurrence of injuries in traffic accidents. Speeding is one of the most common driving violations in Iran, and crashes resulting from high speed occur more than crashes due to any other factor [10]. A previous study found that in Iran, $30 \%$ to $40 \%$ of deaths or injuries occur due to speeding [8]. Passing is another important reason that crashes occur in Iran. Many RTIs occur when a driver cannot properly see the road, but nonetheless attempts to pass. Such drivers pose a great risk for other drivers as well.

The population attributable fraction (PAF) is a useful index for estimating the epidemiological burden of a cause of disease. It provides an estimate of how much of the disease burden of a population would be eliminated if the effects of certain causal factors were eliminated from the population [11]. This index is commonly used to justify interventions in the health system by policymakers. PAF calculation is based on a hypothetical reduction of the prevalence of a particular risk factor to zero $[12,13]$.

The high incidence of RTIs is a serious problem in Iran, and two of the main contributing factors are speeding and passing. If these factors were eliminated, a considerable reduction in adverse effects and negative consequences would be achieved. This study aims to estimate the PAF of speeding and passing on rural roads and to present a guide for policymakers and health planners regarding plans for interventions.

\section{MATERIALS AND METHODS}

In this study, all crashes occurring on rural roads in 2012 were investigated using the census method. Special attention was given to RTIs involving at least one motor vehicle with more than two wheels. Overall, 70,963 traffic crashes that occurred on rural roads in Iran were analyzed. Frequencies, percentages, and the chi-square test were used to analyze the epidemiological characteristics of the RTIs.

We used the comparative risk assessment (CRA) methodology to estimate the PAF of the two modified risk factors of RTIs that we investigated. The CRA methodology can be defined as the evaluation of the changes in population health that occur as the result of modifying the population distribution of exposure to a risk factor [14]. For the estimation of PAF, both estimates of the prevalence and effect size are needed.

\section{Data source for the prevalence of risk factors}

In order to calculate the prevalence of speeding and passing to be used in the PAF calculation, the data registry of the national police forces was used to obtain and study form CAM 114. This is a form that police officers use at the scene of RTIs to record information related to the events as well as the reason for their occurrence in the following five major sections: information related to the conditions in which the crash occurred, characteristics of the involved vehicle(s), road conditions, characteristics of the driver, and the applicable traffic laws. These forms are used in fatal crashes, crashes in which injuries take place, and property-damage crashes on both urban and rural roads.

In this study, rural crashes were considered and urban crashes were excluded.The prevalence of speeding and passing was obtained separately for fatal crashes and crashes resulting in injuries. The total population was used after subtracting the number of drivers for whom no information had been recorded regarding speeding and passing.

\section{Data source for the effect size of risk factors}

In this study, the effect sizes for speeding and passing were obtained using odds ratios (ORs). Statistical analysis was performed using SPSS version 20.0 (IBM Corp., Armonk, NY, USA), and the effect sizes were obtained through logistic regression analysis. The effect size was calculated separately for deaths and injuries. For each factor, the $95 \%$ confidence intervals associated with the ORs were estimated. In order to control for confounding effects, variables regarding human factors, road defects, characteristics of the road surface, safety belt use, age, sex, education level, and occupation were adjusted for in the logistic regression model. ORs were calculated from data incorporating all registered crashes that took place on rural roads in Iran during the study period, such that the data were representative of all crashes in the country.

\section{Estimation of the population attributable fraction}

In order to calculate the PAF, the information related to the prevalence of risk factors and their effect size obtained using the above methods was entered into Equation (1). Subsequent$\mathrm{ly}$, the joint effect of both factors was estimated using Equation (2) [15]. In the following formula, $P$ is the prevalence of risk factors and $O R$ refers to the effect sizes of the risk factors. Risk factor-attributable deaths were estimated using Equation (3).

$$
\begin{aligned}
& P A F=P \times(O R-1 / O R) \\
& P A F=1-\prod_{i=1}^{n}\left(1-P A F_{i}\right)
\end{aligned}
$$

Attributable deaths $=\mathrm{PAF} \times$ total deaths or injuries Equation (3)

The total number of deaths and injuries was obtained through police records. 


\section{RESULTS}

The general characteristics of the population studied are presented in Table 1. On the basis of the data obtained from police records, among 70,963 crashes in rural areas, speeding was involved in $30 \%$ of fatal crashes and $27 \%$ of crashes that led to injuries. Passing was involved in $16.5 \%$ of fatal crashes and $21 \%$ of crashes that involved injuries. Additionally, the upper and lower limits of risk factor prevalence were estimated. The effect size index used to estimate the PAF was the adjusted OR. For speeding, the adjusted OR was calculated to be 3.32 for fatal crashes and 2.60 for crashes involving injuries. The corresponding values for passing were 5.51 and 2.78 , respectively.

The odds of death in accidents involving speeding group was
3.32 compared to accidents in which speeding was not involved. Additionally, the odds of injuries in accidents involving speeding was 2.60 compared to accidents in which speeding was not involved. Similar results were found for passing. The PAF for speeding leading to death at the scene of the crash was 20.96 and the corresponding value was 16.61 for injuries. For passing, these values were estimated to be 13.50 and 13.44 , respectively. The PAF of these two risk factors considered jointly was 31.63 for deaths and 27.81 for injuries. This indicates that 574 deaths and 3,495 injuries would be preventable if the speeding prevalence were to fall to zero, while 370 deaths and 2,822 injuries would be preventable if passing were eliminated. The elimination of both of these risk factors would lead to the prevention of 867 deaths and 5,854 injuries.

Table 1. General characteristics of the population studied

\begin{tabular}{|c|c|c|c|c|}
\hline Characteristics & Deaths & Injuries & No injuries & p-value \\
\hline Sex & & & & $<0.001$ \\
\hline Male & $2,659(96.9)$ & $20,446(97.1)$ & 46,034 (97.6) & \\
\hline Female & $85(3.1)$ & $611(2.9)$ & $1,128(2.4)$ & \\
\hline Age (yr) & & & & $<0.001$ \\
\hline $0-14$ & $5(0.2)$ & $151(0.7)$ & $178(0.4)$ & \\
\hline $15-29$ & 874 (31.9) & $7,679(36.5)$ & $14,117(29.9)$ & \\
\hline $30-44$ & $1,205(43.9)$ & $8,617(40.9)$ & $21,407(45.4)$ & \\
\hline $45-59$ & $554(20.2)$ & $3,771(17.9)$ & 9,869 (20.9) & \\
\hline $60-74$ & $89(3.2)$ & $772(3.7)$ & $1,475(3.1)$ & \\
\hline$\geq 75$ & $17(0.6)$ & $67(0.3)$ & $116(0.2)$ & \\
\hline \multicolumn{5}{|l|}{ Education level } \\
\hline No high school diploma & 746 (27.2) & $6,099(29.0)$ & 16,635 (35.5) & \\
\hline High school diploma & $864(31.5)$ & $6,829(32.4)$ & $16,837(35.7)$ & \\
\hline College degree & $100(3.6)$ & $656(3.1)$ & $3,396(7.2)$ & \\
\hline Unknown & $1,034(37.7)$ & $7,473(35.5)$ & $10,294(21.8)$ & \\
\hline Occupation & & & & $<0.001$ \\
\hline Military & $32(1.2)$ & $174(0.8)$ & $451(1.0)$ & \\
\hline Official & $56(2.0)$ & $375(1.8)$ & $1,594(3.4)$ & \\
\hline Driver & $348(12.7)$ & $2,108(10.0)$ & $7,356(15.6)$ & \\
\hline Unemployed & $18(0.7)$ & $244(1.2)$ & $652(1.4)$ & \\
\hline Other & $2,290(83.5)$ & $18,151(86.2)$ & $37,109(78.7)$ & \\
\hline Driver had a license & & & & $<0.001$ \\
\hline Yes & $2,602(94.8)$ & $19,558(92.9)$ & 96,495 (98.6) & \\
\hline No & $142(5.2)$ & $1,499(7.1)$ & $667(1.4)$ & \\
\hline Safety belt used & & & & $<0.001$ \\
\hline Yes & $1,109(40.4)$ & $8,946(42.5)$ & 11,255 (23.9) & \\
\hline No & $635(23.1)$ & $4,714(22.4)$ & $1,247(2.6)$ & \\
\hline Unknown & $1,000(36.4)$ & $7,397(35.1)$ & $34,660(73.5)$ & \\
\hline Vehicle type & & & & $<0.001$ \\
\hline Personal car & $1,200(3.1)$ & $10,253(26.2)$ & $27,716(70.8)$ & \\
\hline Minibus & $42(5.1)$ & $246(29.8)$ & $538(65.1)$ & \\
\hline Bus & $89(8.8)$ & $200(19.9)$ & 718 (71.3) & \\
\hline Pickup & $263(4.0)$ & $2,022(3.1)$ & $4,245(65.0)$ & \\
\hline Small truck & $150(4.4)$ & $867(25.7)$ & $2,356(69.8)$ & \\
\hline Truck & $287(4.2)$ & $1,427(20.9)$ & $5,117(74.9)$ & \\
\hline Motorcycles & $356(5.9)$ & $4,421(71.4)$ & $1,405(22.7)$ & \\
\hline Trailer & $6(3.1)$ & $39(20.2)$ & $148(76.7)$ & \\
\hline Agricultural machinery & $41(8.8)$ & $239(51.5)$ & $184(39.7)$ & \\
\hline Taxi & $27(2.5)$ & $277(25.4)$ & $785(72.1)$ & \\
\hline Other & $19(10.8)$ & $93(45.9)$ & 201 (40.3) & \\
\hline
\end{tabular}

Values are presented as number (\%). 
Table 2. Percentage of population attributable fraction (PAF) associated with the prevalence and effect size of the risk factors

\begin{tabular}{|c|c|c|c|c|c|c|}
\hline \multirow[b]{2}{*}{ Risk factor } & \multirow{2}{*}{$\begin{array}{l}\text { Outcome of } \\
\text { crash }\end{array}$} & \multirow{2}{*}{$\begin{array}{c}\text { Percentage of } \\
\text { crashes }(95 \% \mathrm{Cl})\end{array}$} & \multirow[b]{2}{*}{ OR $(95 \% \mathrm{Cl})$} & \multicolumn{3}{|c|}{ Percentage of PAF considering } \\
\hline & & & & $\begin{array}{c}\text { Point estimate } \\
\text { of OR }\end{array}$ & $\begin{array}{l}\text { Lower- limit point } \\
\text { estimate of OR }\end{array}$ & $\begin{array}{l}\text { Upper-limit point } \\
\text { estimate of OR }\end{array}$ \\
\hline Speeding & $\begin{array}{l}\text { Death } \\
\text { Injury }\end{array}$ & $\begin{array}{l}30.0(29.6,30.4) \\
27.0(26.2,27.8)\end{array}$ & $\begin{array}{l}3.32(2.75,3.93) \\
2.60(2.27,2.92)\end{array}$ & $\begin{array}{l}20.96 \\
16.61\end{array}$ & $\begin{array}{l}19.09 \\
15.10\end{array}$ & $\begin{array}{l}22.36 \\
17.75\end{array}$ \\
\hline Passing & $\begin{array}{l}\text { Death } \\
\text { Injury }\end{array}$ & $\begin{array}{l}16.5(15.8,17.2) \\
21.0(19.4,22.6)\end{array}$ & $\begin{array}{l}5.51(5.40,5.61) \\
2.78(2.54,3.01)\end{array}$ & $\begin{array}{l}13.50 \\
13.44\end{array}$ & $\begin{array}{l}13.55 \\
12.73\end{array}$ & $\begin{array}{l}13.44 \\
14.02\end{array}$ \\
\hline Joint effect of both risk factors & $\begin{array}{l}\text { Death } \\
\text { Injury }\end{array}$ & & & $\begin{array}{l}31.63 \\
27.81\end{array}$ & $\begin{array}{l}30.05 \\
25.90\end{array}$ & $\begin{array}{l}32.79 \\
29.28\end{array}$ \\
\hline
\end{tabular}

$\mathrm{Cl}$, confidence interval; OR, odds ratio.

The PAF values for the upper and the lower limits of prevalence, the estimated ORs for each of the risk factors alone, and the joint effect of both risk factors are presented in Table 2 .

\section{DISCUSSION}

Our findings demonstrated that drivers who engaged in speeding and passing had a higher risk of death or injury. According to our results, if we could reduce the prevalence of speeding to zero, $20.96 \%$ of deaths occurring at the crash scene and $16.61 \%$ of injuries would be preventable. The corresponding values for passing are $13.50 \%$ and $13.44 \%$. If both risk factors were eliminated completely, $31.63 \%$ of deaths occurring at the crash scene and $27.81 \%$ of injuries would be prevented.

The relationship between speeding and RTIs has been well established. Numerous studies have examined the relationship between speeding and crash risk. In these studies, it has been shown that high-speed vehicles are at a much higher risk of crash than low-speed vehicles [16]. Additionally, with increased speed, death and injuries resulting from traffic accidents increase $[17,18]$. It has been estimated that increased speed on interstate roads and freeways can lead to a $15 \%$ increase in deaths resulting from traffic accidents [19]. A $1 \%$ increase in speed is associated with an approximately $2 \%$ increase in the rate of crashes involving injuries, a 3\% increase in the severe crash rate and a $4 \%$ increase in the fatal crash rate [20]. Hence speeding is directly related to an increase in crash severity.

This study showed that speeding is one of the most important risk factors contributing to RTIs in Iran, and that by reducing it to zero and eliminating this risk factor we could prevent many traffic deaths and injuries. Although the relationship between speeding and traffic crashes is very complicated, speed is a clear contributing factor to the severity of a crash. At high speed, it is more probable for the driver to lose control of the vehicle, and the resultant possibility of overcorrection in combination with an impaired reaction time leads to an increased probability of crashing, injury, and death [7].
Passing, which is the result of a sensitive judgment made by the driver, is an important risk factor. One study reported that $10 \%$ of deaths occurred as a result of, passing [21]. This factor accounted for $7.9 \%$ of fatal road accidents in the county of Nottinghamshire, England, during the period from 1989 to 1992, and the accident severity index associated with passing (the proportion of cases resulting in deaths or serious injuries) was over $20 \%$ [22].

This study showed that passing was just as important as speeding as a risk factor, and that reducing passing to the lowest possible level will considerably increase road safety and prevent a large number of deaths and injuries.

A strength of this study is that it derived the current distribution of risk factors from a national source, namely the national traffic police data registry, using valid and reliable tools. However, police data are the only available source for such data that can be used in Iran. These data only include deaths that occurred at the crash scene, not deaths that may have occurred later as a result of RTIs. Therefore, we believe that the possibility of having underestimated the ORs could be considered a limitation of our study.

Additionally, a possible limitation of this study results from the fact that form CAM 114 is completed at the scene of crashes, meaning that death or emotional distress on the part of the driver could result in the omission of some data.

The PAF can be a helpful tool for showing the preventable fraction of deaths associated with a risk factor, if it were to be eliminated. However, this method involves some limitations; for diseases or injuries with multiple risk factors, the PAF may be overestimated because multiple ways may exist to prevent diseases with more than one risk factor.

Speeding and passing are dangerous behaviors with a high prevalence in Iran. Speeding was found to be more prevalent and to play a larger role in traffic accidents causing injury or death than passing. The PAFs for these two factors suggest that controlling speeding should take priority over passing, so it is recommended that related legislation should be considered more seriously and enforced more rigorously. Lastly, it is noteworthy 
that considering the joint effect of these risk factors considerably increases the PAF.

\section{ACKNOWLEDGEMENTS}

The authors would like to thank the traffic police of the Islamic Republic of Iran for their valuable cooperation.

\section{CONFLICT OF INTEREST}

The authors have no conflicts of interest to declare for this study

\section{ORCID}

Fatemeh Khosravi Shadmani http://orcid.org/0000-00025172-7950

Hamid Soori http://orcid.org/0000-0002-3775-1831

Kamyar Mansori http://orcid.org/0000-0001-5008-8547

Manoochehr Karami http://orcid.org/0000-0002-9026-3757

Erfan Ayubi http://orcid.org/0000-0002-8829-9304

Salman Khazaei http://orcid.org/0000-0001-5918-2310

\section{REFERENCES}

1. Ditsuwan V, Veerman LJ, Barendregt JJ, Bertram M, Vos T. The national burden of road traffic injuries in Thailand. Popul Health Metr 2011;9:2.

2. Hyder AA, Amach OH, Garg N, Labinjo MT. Estimating the burden of road traffic injuries among children and adolescents in urban South Asia. Health Policy 2006;77:129-139.

3. Soori H, Hatam Abadi HR, Vafaei R, Hadadi M, Ayni E, Asna Ashari HR. Pattern epidemiologic road traffic injuries Tehran-Abali road: a cohort study. Payesh 2010;11:29-37 (Persian).

4. Hesari A, Esmaeili A. Estimates of deaths and injuries from traffic accidents in his life expectancy at birth and its associated economic burden in 2002. J Healthc Manag 2004;2:27-35 (Persian).

5. Ardalan A, Masoomi GR, Goya MM, Sarvar MR, Haddadi M, Miadfar J, et al. Road traffic injuries: a challenge for Iran's health system. Iran J Public Health 2009;38:98-101.

6. Alikhah F, Pakseresht S. Promoting proper traffic culture: the experience of two developed countries; 2009 [cited 2012 Apr 15]. Avail- able from: http:// www.wikipg.com show_context.php (Persian).

7. Soori H, Ebn Ahmadi A, Ashrafi Hafez A, Hatam Abadi HR, Hadadi M, Ayni E, et al. Speed management: a road safety manual for decicion-makers and practitioners. Tehran: Research Center of NAJA; 2009, p. 75 (Persian)

8. Safarzadeh M, Abolhassannejad V. Introducing a method for programming the installation of traffic calming facilities and instruments. Tehran: Sevilica; 2007 (Persian).

9. Mao Y, Zhang J, Robbins G, Clarke K, Lam M, Pickett W. Factors affecting the severity of motor vehicle traffic crashes involving young drivers in Ontario. Inj Prev 1997;3:183-189.

10. Sanaei-Zadeh H, Vahabi R, Nazparvar B, Amoei M. An epidemiological study and determination of causes of traffic accident-related deaths in Tehran, Iran (during 2000-2001). J Clin Forensic Med 2002; 9:74-77.

11. Rockhill B, Newman B, Weinberg C. Use and misuse of population attributable fractions. Am J Public Health 1998;88:15-19.

12. Karami M, Khosravi Shadmani F, Najafi F. Estimating the contribution of diabetes on the attributable burden of cardiovascular diseases in Kermanshah, West of Iran. Iran J Epidemiol 2012;8:33-38 (Persian).

13. Karami M, Soori H, Monfared AB. Estimating the contribution of selected risk factors in attributable burden to stroke in Iran. Iran J Public Health 2012;41:91-96.

14. Ezzati M, Lopez AD, Rodgers A. Murray CJ. Comparative quantification of health risks: global and regional burden of disease attributable to selected major risk factors; 2004 [cited 2016 Sep 16]. Available from: http://www.who.int/publications/cra/chapters/volume1/ 0000i-xxiv.pdf.

15. Aarts L, van Schagen I. Driving speed and the risk of road crashes: a review. Accid Anal Prev 2006;38:215-224.

16. Retting RA, Greene MA. Traffic speeds following repeal of the national maximum speed limit. ITE J 1997;67:42.

17. Najjar YM, Stokes RW, Russell ER, Ali HE, Zhang X. Impact of new speed limits on Kansas highways; 2000 [cited 2016 Sep 16]. Available from: http://ntl.bts.gov/lib/11000/11100/11138/KSU983. pdf.

18. Kockelman K. Safety impacts and other implications of raised speed limits on high-speed roads. Washington, DC: Transportation Research Board; 2006, p. 1-197.

19. Retting R, Cheung I. Traffic speeds associated with implementation of $80 \mathrm{mph}$ speed limits on West Texas rural interstates. J Safety Res 2008:39:529-534.

20. Fuller R, Gormley M, Stradling S, Broughton P, Kinnear N, O'Dolan $\mathrm{C}$, et al. Impact of speed change on estimated journey time: failure of drivers to appreciate relevance of initial speed. Accid Anal Prev 2009; 41:10-14.

21. Jamson S, Chorlton K, Carsten O. Could intelligent speed adaptation make overtaking unsafe? Accid Anal Prev 2012;48:29-36.

22. Clarke DD, Ward PJ, Jones J. Overtaking road-accidents: differences in manoeuvre as a function of driver age. Accid Anal Prev 1998;30: 455-467. 